BULLETIN Bulletin hispanique

HISPANIQUE Université Michel de Montaigne Bordeaux

117-1 | 2015

Les poètes des rhéteurs

Karim Benmiloud y Raphaël Estève (dir.), El planeta

Pitol

Presses Universitaires de Bordeaux, Bordeaux, 2012

Isabelle Tauzin-Castellanos

\title{
OpenEdition
}

Journals

Edición electrónica

URL: https://journals.openedition.org/bulletinhispanique/3945

DOI: 10.4000/bulletinhispanique.3945

ISSN: 1775-3821

Editor

Presses universitaires de Bordeaux

Edición impresa

Fecha de publicación: 1 junio 2015

Paginación: 390-392

ISBN: 979-10-300-0174-7

ISSN: 0007-4640

Referencia electrónica

Isabelle Tauzin-Castellanos, «Karim Benmiloud y Raphaël Estève (dir.), El planeta Pitol», Bulletin

hispanique [En línea], 117-1 | 2015, Publicado el 01 septiembre 2015, consultado el 12 febrero 2022.

URL: http://journals.openedition.org/bulletinhispanique/3945 ; DOI: https://doi.org/10.4000/

bulletinhispanique.3945

Este documento fue generado automáticamente el 12 febrero 2022.

Tous droits réservés 


\section{Karim Benmiloud y Raphaël Estève (dir.), El planeta Pitol}

Presses Universitaires de Bordeaux, Bordeaux, 2012

Isabelle Tauzin-Castellanos

\section{REFERENCIA}

Karim Benmiloud y Raphaël Estève (dir.), El planeta Pitol, Bordeaux, Presses Universitaires de Bordeaux, 2012, 370 p. Collection MPI, série Amériques.

ISBN 978-2-86781-797-7.

1 El planeta Pitol es mucho más que la simple yuxtaposición de trabajos presentados en un coloquio internacional. Un sentimiento de júbilo trasciende desde el prólogo y recuerda la emoción de los participantes en el evento que contó con la presencia de Sergio Pitol, llegado ex profeso de Veracruz a Burdeos. El título «El planeta Pitol» connota a la vez el cosmopolitismo y la universalidad del escritor mexicano. Entre lo global y lo local, Pitol resulta utópico, a medio camino entre Moscú y Xalapa. El libro se abre con una nota del novelista, y las charlas amistosas de Enrique Vila-Matas, Jorge Herralde y Álvaro Enrigue que apuntan la sensibilidad del premio Cervantes, capaz de trasfigurar temas afines al naturalismo decimonónico en relatos fantásticos perennes. Biografía y bibliografía convierten la recopilación de estudios científicos en manual universitario asequible a todos. El lector recorre la obra de Pitol, los cuentos iniciales de Tiempo cercado como las novelas reunidas en Tríptico del carnaval y los escritos misceláneos.

Russel M. Cluff presta atención a aquellas ficciones publicadas entre 1959 y 1970 . Halla personajes que predicen la vida del autor, explora viajes y destierros de unos protagonistas triviales, antes que el novelista se convierta en diplómatico de vida igualmente nómada. Cluff muestra cómo en Pitol el ensayo se engasta en la ficción y viceversa, de tal modo que la verdad se entreteje con la imaginación como antes sucediera con Alfonso Reyes. A continuación comprueba Federico Bravo la conciencia metalingüística del novelista a partir del cuento «Hacia Varsovia» que permite abrir la 
caja negra de la escritura, y descubrir cómo la forma es el fondo. En Pitol, todo se invierte, pudiendo ser leído al revés, o entre líneas, hasta las erratas del editor. En «De los perfiles de Vals de Mefisto» Eduardo Ramos Izquierdo analiza el anidamiento del cuento dentro del cuento; pone de manifiesto la cosmovisión pitoliana tan entremezclada con el discurso metaficcional que «son textos para ser releídos que ganan espesor en cada nueva lectura» (141).

Marie José Hanaï pone de realce los estrechos vínculos entre investigación histórica y narrativa policial a partir de la reconstrucción del año 42 en El desfile del amor, siguiendo las lucubraciones del héroe a la vez historiador y detective. La primera novela del Tríptico del carnaval extravía al lector entre las nimiedades de los protagonistas y las alusiones a la vida político-cultural en momentos del auge del fascismo. Karim Benmiloud aclara la complejidad de El desfile del amor siguiendo los pasos del crítico Roland Barthes, estudioso del enigma Sarrasine, un cuento de Balzac que pudo inspirar al escritor mexicano. Benmiloud comenta el motivo del doble, subyacente a lo largo de la novela, «entre la reduplicación y la diferenciación, la copia y el original, el mismo y el otro» (195); se terminan diluyendo las identidades. El mexicanista francés intuye la forma cómo Pitol infiltra la referencia histórica de modo anodino en el enigma policial del asesinato del Minerva ocurrido en 1942. El narrador consigue enlazar la Historia con las artes más desvinculadas, tanto la comedia tirsiana como el cine nacional. El desdoblamiento resulta el rasgo distintivo de la parodia en una obra de ficción que caricaturiza la sociedad posrevolucionaria como lo hizo Buñuel en El ángel exterminador a inicios de los 60. Para rematar, Karim Benmiloud descifra el misterio del título, un guiño a la película de Lubitsch de 1929 The Love Parade, y se revela como hermeneuta del novelista bajtiniano.

Mediante el análisis del comportamiento y los pensamientos de Dante de la Estrella, Raphaël Estève explora la especularidad en Domar a la divina garza. El lector sigue los pasos del crítico literario y observa que el resentimiento y los celos corrompen las relaciones hacia la figura de la sabiduría, aquella «divina garza» a la que un literato ramplón quiere «domar». En densas páginas, con herramientas nietzcheanas y excluyendo la jerigonza, Estève llega a hacernos compartir la irrisión omnipresente en esta segunda novela. Erich Fisbach dedica un artículo sintético y convincente a La vida conyugal (1991); explora los recursos estilísticos y relaciona la ficción con el realismo francés, especialmente con Madame Bovary y La mujer de treinta años, obra menos conocida de Balzac. El humor de Sergio Pitol se disemina en los análisis literarios de sendos estudiosos.

El planeta Pitol nos brinda además un trabajo de Alejandro Hermosillo Sánchez. Éste demuestra que Veracruz precozmente asoma en la narrativa pitoliana, como mundo secreto anterior a los paseos eslavos. También corrobora que la crítica global y local no se excluyen en el mexicano como tampoco sucedía con García Márquez entre Aracataca y el espacio latinoamericano. Maricruz Castro Ricalde sigue la misma línea de investigación, explorando El viaje, un texto híbrido mediante el cual Pitol indaga los dramas vividos por los artistas a lo largo de la historia soviética; en esas páginas cargadas de compasión y empatía «interesa tanto lo enunciado como el proceso de la enunciación» (302); el escritor se identifica con las víctimas de la ideología dominante, el lector de inicios del siglo XXI descubre la ambivalencia de la Europa oriental en tiempos de la Glasnost tal como la vio Sergio Pitol. 
6 Con gracia Liliana Kancheva Tabákova recuerda su primer encuentro con el escritor por los años 80, cuando hizo sus pinitos como traductora. Da cuenta de una gran cantidad de detalles que permiten un conocimiento casi del interior de la obra pitoliana, y explican que el mexicano llegó a practicar el diálogo intercultural antes de que la interculturalidad pasara a ser una moda en manos de los científicos sociales. La narrativa de Sergio Pitol se parece a una fuga en el doble sentido de la palabra, escapatoria de media vida hacia Europa y contrapunto musical que enlaza en forma imperceptible, como cajas chinas, figuras y temas a la vez próximos y alejados como lo señala Peter G. Broad.

7 En resumidas cuentas, El planeta Pitol abarca toda la obra del escritor mexicano hasta las celebraciones del bicentenario. Con este trabajo la seriedad académica se compagina con la elegancia y despierta curiosidad hacia una narrativa largo tiempo ignorada acá, y allá unánimemente elogiada. El planeta Pitol resulta un libro polifacético, a imagen y semejanza del escritor homenajeado en la universidad de Burdeos por la feliz iniciativa de los autores: Karim Benmiloud y Raphaël Estève.

\section{AUTORES}

\section{ISABELLE TAUZIN-CASTELLANOS}

Université Bordeaux Montaigne 